\title{
Vertical Distribution and Elevation Preference for the Breeding of Fairy Pittas on Jeju Island, Korea
}

\author{
Eun-Mi Kim ${ }^{1,2}$, Chang-Wan Kang ${ }^{2,3}$, Chang-Yong Choi ${ }^{2,4, *}$, Jung-Hwa Chun ${ }^{5}$ and \\ Hyun-Young Nam ${ }^{2,6}$ \\ 1 Warm Temperate and Subtropical Forest Research Center, National Institute of Forest Science, Jeju 63582, \\ Korea; kptta@naver.com \\ 2 Jeju Nature Park, Seowipo, Jeju 63630, Korea; jejubirds@daum.net (C.-W.K.); stern23@snu.ac.kr (H.-Y.N.) \\ 3 The Korea Association for Bird Protection Jeju Branch, Seogwipo, Jeju 63541, Korea \\ 4 Research Institute of Agriculture and Life Sciences, Seoul National University, Seoul 08826, Korea \\ 5 Research Planning and Coordination Division, National Institute of Forest Science, Seoul 02455, Korea; \\ chunjh69@korea.kr \\ 6 School of Biological Sciences, Seoul National University, Seoul 08826, Korea \\ * Correspondence: sub95@snu.ac.kr; Tel.: +82-2-880-4766
}

Received: 16 September 2019; Accepted: 7 November 2019; Published: 12 November 2019

\begin{abstract}
Elevation often becomes an important component in the breeding site selection of forest birds because it may affect individual fitness. To understand how the threatened fairy pitta (Pitta nympha Temminck \& Schlegel) selects a particular elevation for breeding and whether the pitta achieves better reproductive performance in its preferred elevation, we surveyed for the presence of breeding pittas and recorded their reproductive performances at six different elevation zones on Mount Halla in Jeju Island, Korea. We expected that preference for breeding sites and reproductive performance would gradually decrease with increasing elevation. In fact, 73 presence and 78 absence records indicated no preference for breeding sites at elevations lower than $400 \mathrm{~m}$. However, forest habitats between 400 and $600 \mathrm{~m}$ were strongly preferred, while locations above $800 \mathrm{~m}$ were clearly avoided. The egg-laying date was significantly earlier at lower elevations, but other measures of reproductive performance did not differ between the preferred and non-preferred elevations. Contrary to our expectations, this indicates that there was no clear advantage to a pitta's reproductive performance based on elevation preference. Our findings suggest that the inherent optimal selection for the best reproductive outcomes was not a key driving factor for the pattern of elevation preference observed, and that the pitta's preference might be a response to external and environmental factors such as climate conditions. The reduction of anthropogenic impacts by mitigating human-pitta conflicts at lower elevations, such as accidental non-reproductive mortality and forest loss, would help enhance the conservation of the fairy pitta on Jeju Island, a stronghold of this threatened species in Korea.
\end{abstract}

Keywords: elevation; Pitta nympha; preference; reproductive performance; selection; conservation

\section{Introduction}

The habitat selection of birds, especially breeding site selection, is often regarded as a non-random process of natural selection because it may affect individual fitness [1,2]. In particular, breeding or nesting site selection is often closely linked with individual fitness, including survival and reproductive performance; therefore, such choices are under diverse and strong selection pressures [2-4]. Higher elevation is often characterized by lower temperatures, delayed plant phenology, unstable climates, reduced food supply and habitat quality, and lower nest site availability, which affect many aspects of avian ecology [5-7]. Therefore, elevation often becomes an important component in the 
breeding site selection of forest birds because it influences many reproductive aspects like the clutch size and egg size [6], the timing of breeding and reproductive investments [7], and predation risks [8].

The fairy pitta (Pitta nympha Temminck \& Schlegel) is an obligate migrant breeding in forest environments in the Korea (hereafter Korea), China, Taiwan, and Japan, and it is believed to spend winter in Southeast Asian countries [9]. Its breeding habitats in forests have been largely disturbed and reduced by diverse anthropogenic factors such as deforestation, forest fires for slash and burn farming, unsustainable forest management, the logging and harvesting of forest products, residential and commercial developments, the construction of roads and dams, and illegal trapping $[9,10]$ as well as physical collisions with man-made structures [11]. In addition to the small global population of only 1500-7000 mature individuals and their limited geographic distribution, confined to East Asia, these threats have resulted in a trend of decline for the pitta, such that it is now a vulnerable species on the IUCN (International Union for Conservation of Nature) Red List [9]. Although the general biology of breeding fairy pittas has been described [9-13], detailed information is still limited due to its elusive behavior at breeding sites, which are often associated with dense forests and forested valleys [12,13].

The fairy pitta is known as a breeder in lowland forests, and its upper limit of elevation seems to be $1200 \mathrm{~m}[9,10]$. More specifically, the pitta in Taiwan was observed at elevations from sea level to $980 \mathrm{~m}$, but more than $75 \%$ of them were observed at elevations lower than $280 \mathrm{~m}$ [14]. In Korea, Kim et al. [15] reported that the vertical distribution of breeding pairs on Jeju Island ranged from 50 to $800 \mathrm{~m}$, and about $91 \%$ of them were confirmed in forests at less than $600 \mathrm{~m}$. However, this report in Korea contradicts previous older records documented in the 1960s that the pittas were distributed between 1200 and $1600 \mathrm{~m}$ [16] and bred between 1000 and $1200 \mathrm{~m}$ [17] on the same island. During the 1980s, this species was reported in forested areas at 500-600 $\mathrm{m}[18,19]$. This inconsistency among the previous reports of the pitta's occurrence along the elevation gradient on Mount Halla, which supports the largest breeding population of the pitta in Korea [20], may lead to great uncertainty in species conservation and habitat management. Kim et al. [21] explained that the inconsistency in the vertical occurrence of breeding pittas on Jeju Island is caused by long-term changes in habitat, vegetation cover, and forest landscapes based on reviews of satellite images, ground-based landscape photos, and the literature. They judged that the forest landscapes of Jeju Island had been improved both in quantity and quality, suggesting increased potential for breeding habitats for the pitta [21]. However, the review study did not examine any direct linkage between the breeding habits of the pitta and the changing forest landscapes in the key breeding area on Jeju Island.

Understanding a pattern for how available habitat differs from breeding habitat is often the first step toward discovering the process of natural selection for breeding-site selection [2]. Given the unknown pattern of vertical selection of breeding sites by the threatened fairy pitta, the aim of this study was to understand the breeding habitat preference along the elevation gradient of forests on Mount Halla and to test the hypothesis that the pitta selectively prefers a particular elevation to achieve better reproductive performance (e.g., the egg-laying date, clutch size, number of hatchlings, and number of fledglings). Specifically, because the common breeding habitats of pittas were known to be lower elevation forests $(<600 \mathrm{~m})[14,15]$, we expected that the breeding site preference and reproductive performance would gradually decrease with increase in elevation. In this paper, we discuss our findings as the vertical distributions of pittas may relate to the potential influences of forest habitat change in the context of the pitta conservation on Jeju Island, the Korea.

\section{Materials and Methods}

\subsection{Study Area}

Our study area was Mount Halla (or Hallasan; $33^{\circ} 21^{\prime}$ N, $126^{\circ} 32^{\prime}$ E) on Jeju Island, Jeju Province, in the Korea. Jeju Island is a volcanic island located in the southernmost part of Korea and belongs to a semitropical climate zone [22]. During the breeding season of fairy pittas (May to August), the island has a mean temperature of $22.7^{\circ} \mathrm{C}$ and average precipitation of $228.3 \mathrm{~mm}$ [22]. Mount Halla is a shield 
volcano on Jeju Island and is the highest mountain in Korea with its summit about $1950 \mathrm{~m}$ above sea level. The gradual change in elevation from the coastline to the summit on Mount Halla forms diverse microclimates and microhabitats for wildlife.

The fairy pitta was known as a rare breeding bird on Jeju Island, but Kim [20] confirmed that more than 60 pairs breed annually on the island. This finding indicated that the island supports the largest known breeding population in Korea and that the Jeju population seems to be the stronghold of this threatened species in Korea.

\subsection{Field Survey}

Based on previous studies on the habitat use of fairy pittas [15], we identified potential breeding habitats of the species that should include broad-leaved and evergreen forests larger than 3 ha in size. We also considered that the potential habitats were dominated by tall trees $(>10 \mathrm{~m})$ with no dense vegetation on the forest floors and were well-shaded, humid areas (average humidity of $70 \%-80 \%$ ) with a mean temperature of $20-25^{\circ} \mathrm{C}$ in June and July [15]. After identification of the potential breeding habitats of fairy pittas, we grouped them into six elevation zones from sea level to $1200 \mathrm{~m}$ above sea level at $200 \mathrm{~m}$ intervals. A total of 151 survey sites were selected and surveyed between 2002 and 2017: 27 sites were at $0-200 \mathrm{~m}, 39$ were at $200-400 \mathrm{~m}, 49$ were at $400-600 \mathrm{~m}, 20$ were at $600-800 \mathrm{~m}$, 9 were at $800-1000 \mathrm{~m}$, and 7 sites were at 1000-1200 m. Despite records in the older literature [16], we did not consider higher elevations $(>1200 \mathrm{~m})$ as potential habitat for the pitta because there is no confirmed breeding record of this species there since 2000. Because the fairy pittas are present between May and September in Jeju [11], we carried out playback surveys using recordings of the pitta's song between 20 May and the end of August to confirm the occurrence of breeding pairs at 151 sites: 103 sites between 2002 and 2003, 30 in 2011, and 18 in 2017. The sites were repeatedly visited and the playback survey was performed twice a week in May (arrival, territory establishment, and nest building stages), and three times a week between June to August (nest-building, egg-laying, brooding, and fledging stages) in 2002, 2003, and 2011 [15], while the 18 sites in 2017 were surveyed once or twice in June. Two or more observers remained stationary while playing back recordings at a randomly-selected position in each site. One cycle of the survey included the playback of a recorded pitta song for 30 seconds, and then pausing for 10 seconds to wait for pitta responses; we repeated three cycles in each site to detect any response of the pittas [15]. We used different positions for the playbacks at the same site but also visited the same position where the pittas previously responded. When one or more pittas were vocally or visually detected responding to our playbacks in a study site, we confirmed their presence and also searched for their active nests to collect more detailed breeding information at the site. All playback surveys were conducted between sunrise and sunset under affordable weather conditions with good visibility, no precipitation, and light winds.

\subsection{Preference for a Particular Breeding Elevation}

To describe the vertical distribution and elevation preference of the pittas, we used three methods considering their characteristics in resource selection studies: a generalized linear model (GLM), and Jacobs' preference and Manly's selection indices. The GLM can investigate the overall influence of elevation on presence/absence of pittas, and it can predict the pittas' vertical distribution based on the predicted chance of presence (or encounter rate) in each elevation zone [23]. The Jacobs' and Manly's indices are both useful in studies examining the relationship of habitat selection with other variables using the proportions of available and used habitats [24,25]. We used the Jacobs' index to test where there was preference or avoidance in each elevation zone because it can provide values in finite symmetrical scales-negative values $(0$ to -1$)$ for avoidance and positive values $(0$ to 1$)$ for preference [24]. Manly's index with Bonferroni adjustment can provide relative selection values (rather than preference or avoidance) that come with conservative confidence intervals for each elevation zone; we provide here, the standardized selection ratios to interpret the unadjusted selection ratios in asymmetrical scales [25]. 
We tested a hypothesis that elevation had an influence on the probability that a fairy pitta was present on a site using a presence/absence analysis [23]. First, we built a contingency or cross-tabulation table of pitta presence (true $=1$ ) and absence (false $=0$ ) with elevation categories for a chi-square test [23]. Then, we used a generalized linear model (GLM) with a binomial logit link to examine the hypothesis.

In addition, the Jacobs' preference index [24] was used to estimate the preference and avoidance of breeding elevations on Mount Halla (Equation (1)):

$$
D_{i}=\left(r_{i}-p_{i}\right) /\left(r_{i}+p_{i}-2 r_{i} p_{i}\right),
$$

where $p_{i}$ is the proportion of available habitats and $r_{i}$ is that of occupied habitats in each elevation zone $i$. Because this index ranging from -1.0 (avoidance) to 1.0 (preference) provided a single $D_{i}$ for each elevation zone, and we used a bootstrapping method, that is, the easiest and commonly-used method, to estimate the variances of preference indices [25]. To test where there was preference or avoidance at each elevation, and whether preferences were different across the six elevation zones, we performed a bootstrapping analysis through 100 random resamplings. Because the bootstrapping resamples did not pass normality tests, we used one-sample, signed-rank tests to examine whether the mean of the preference was different from zero (which means no preference nor avoidance). The differences in preference among elevations were examined using the Kruskal-Wallis test and all pairwise multiple comparison procedures (Tukey's test).

We also calculated Manly's selection ratio (w; Equation (2)) and standardized selection ratio (B; Equation (3)) [25] as below:

$$
\begin{gathered}
w_{i}=r_{i} / p_{i} \\
B_{i}=\left(r_{i} / p_{i}\right) /\left(\sum r_{i} / p_{i}\right),
\end{gathered}
$$

where $r_{i}$ and $p_{i}$ are the proportions of used and potential breeding habitats, respectively, that are in category $i$, and $u_{i}$ is the number of occupied sites in elevation category $i$. The standardized selection ratio, ranging from 0 to 1 , is a probability that a category $i$ habitat unit would be the next one selected if it was possible to make each of the types of habitat unit equally available [25]. Bonferroni corrected confidence intervals (CI) for proportions used $(r)$ and selection ratios $(w)$ of six elevation groups were estimated with $\alpha ;=0.05 / 6=0.0083$, and their standard errors were calculated, as shown below (Equations (4) and (5)):

$$
\begin{gathered}
r_{i} \pm Z_{\alpha / 2} \sqrt{r_{i}\left(1-r_{i}\right) / \sum u_{i}} \\
w_{i} \pm Z_{\alpha / 2} \sqrt{r_{i}\left(1-r_{i}\right) /\left(\sum u_{i} \times p_{i}^{2}\right)} .
\end{gathered}
$$

\subsection{Reproductive Performance}

Whenever nests of the pittas that responded to our playbacks were found, we recorded breeding parameters such as date of first egg-laying, clutch size, and numbers of nestlings and fledglings for each of the nests found. If not directly observed, the first egg-laying date was estimated based on the number of eggs laid in the egg-laying period or by taking the known incubation period from the hatching date once the clutch size was determined. If at least one chick fledged from a nest, we considered it a successful nest and documented the number of fledglings per successful nest by elevation. We compared the breeding parameters between different elevations using ANOVA and the Kruskal-Wallis test followed by a Tukey test for an all pairwise multiple comparisons when necessary.

We used R software version 3.1.1 [26] for all statistical analyses, and all values are given as means \pm standard deviations (SD) unless otherwise noted. 


\subsection{Changes in the Area of Forests}

To assess forest areas by elevations and changes in those over time, we used Landsat satellite images and output raster maps processed in Kim et al. [21]. The detailed procedures were as follows.

Landsat MSS images (March 1975) and Landsat 7 images (March 2002) were selected to produce landcover maps for two periods. A surface terrain model for rectification was generated by acquiring and mosaicking together topographical maps (1:5000 scale) produced by the National Geographic Information Institute that covered the study area. Both of the images were geometrically rectified to the transverse Mercator coordinate, utilizing ground control points identifiable in the imagery. Radiometric calibration and subsequent transformation to at-satellite reflectance was performed by utilizing standard procedures by Markham and Barker [27]. Then, C-correction [28,29] was applied to the images to correct the reflectance of sun-facing and anti-sun facing slopes utilizing the DEM (digital elevation model) extracted from the topographical maps.

Both the unsupervised and supervised approaches were applied to the classification of the preprocessed images. Original images were converted to PCA (principal component analysis) and NDVI (normalized difference vegetation index) raster data to stack into single, multilayer image files including original bands except for thermal layers.

In order to recognize the spectral characteristics of the diverse ground objects represented in the satellite imagery, an unsupervised training algorithm (isodata) was run on the stacked images to generate appropriate spectral clusters and corresponding signatures.

Field surveys were also conducted over the study period to gather data on the pre-clustered spectral classes. A compass and laser distance-measuring devices were used together with real-time differential GPS (HDOP < 1.5) to identify the locations of certain characteristics. Survey points and the site description data were constructed into a spatial database and utilized for combining the isodata classes and supervised classification.

Based on the unsupervised classification results and ground truth data, a training dataset was created as a group of seeds for extracting the signature of each class for maximum likelihood supervised classification. After each classification process, the classified area and boundaries were visually evaluated based on the ground truth data. If the results were not acceptable, the training dataset was adjusted and the classification process was iterated. Finally, classification results were developed into maps showing six categories of cover, including deciduous forest, conifer forest, cultivated land, barren land, urban area, and water bodies. In this study, only deciduous and conifer forest categories were extracted and their changes assessed over time. The classification accuracy of the forest category was $95 \%$ based on field survey results and aerial photos.

\section{Results}

\subsection{Preference for Breeding Elevation}

We confirmed the occurrence of breeding fairy pittas at 73 out of 151 survey sites (67 of 133 from 2002 to 2011 and six of 18 in 2017), and the breeding pairs occurred in the potential habitats between 50 and $800 \mathrm{~m}$ on Jeju Island, Korea.

Based on the contingency tables developed by the 73 presence and 78 absence records, the proportions of occupied habitats by breeding pittas were significantly different from those of unused habitats across the elevation categories $\left(\chi^{2}=18.754, d f=5, p=0.002\right)$. Binomial GLM with a logit link also confirmed that the predicted chance of pitta presence differed by elevation (AIC $=198.87$, $\left.\chi^{2}=22.293, d f=5, p<0.001\right)$. The predicted chance for pitta presence in the range 400-600 $\mathrm{m}$ was the highest (0.65, 95\% CI: 0.51-0.77) and was significantly different from the probability at 800-1000 m (0.11, 95\% CI: 0.02-0.50) and above, whereas there were wide overlaps between the other elevations (Figure 1a).

Jacobs' preference indices (D) calculated from 100 random resamplings also confirmed the difference in preference by elevation $(d f=5, H=512.579, p<0.001)$ (Figure 1b). There was no preference 
or avoidance at 0-200 m, but preference was documented between 200 and $600 \mathrm{~m}$, while avoidance was found between 600-1200 m. The breeding pittas strongly preferred 400-600 $\mathrm{m}(t=27.820, d f=99$, $p<0.001)$, while they avoided higher elevations (600-800 m: $t=-13.222, d f=99, p<0.001 ; 800-1000 \mathrm{~m}$ : $t=-27.064, d f=99, p<0.001)$.
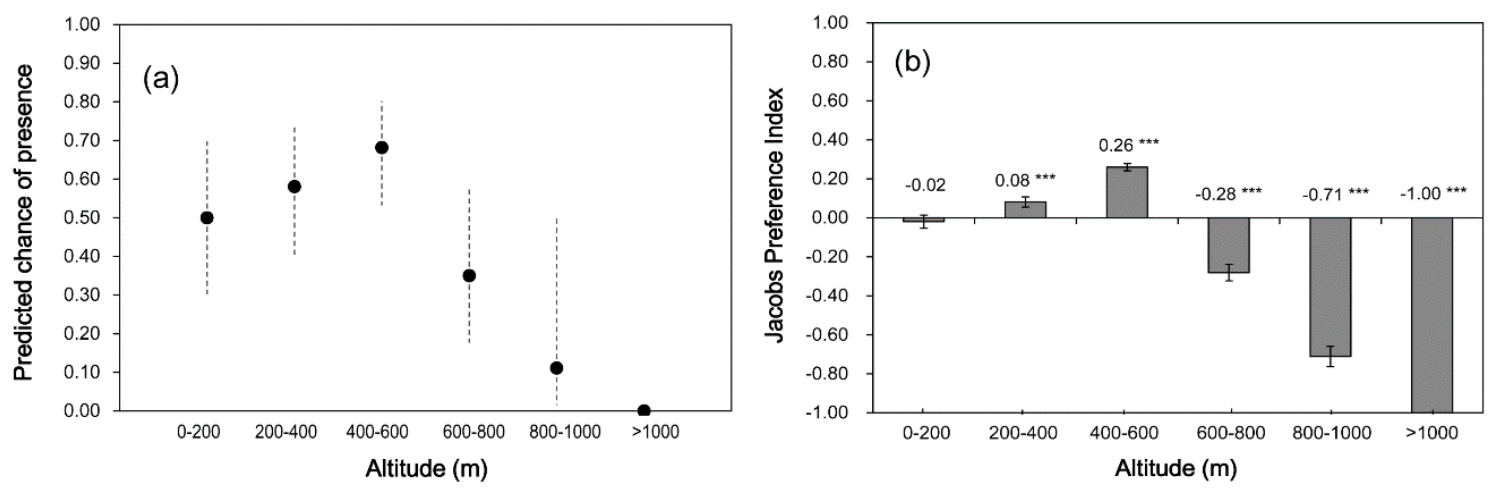

Figure 1. Occurrences and habitat preferences of fairy pittas on Jeju Island, Korea. (a) Predictions for the presence (the $95 \%$ confidence intervals (95\% CI)) of fairy pittas for each elevation category. (b) Changes in the mean Jacob preference index for breeding habitat selection by elevation based on 100 resamplings; vertical bars denote standard deviations. Numeral letters and vertical lines on bars represent the mean preference indices and $95 \%$ confidence limits after 100 bootstrap resamples. Asterisks denote statistically significant differences $\left.{ }^{* * *} p<0.001\right)$ from zero based on a Student's $t$-test for one sample (no preference or avoidance).

We estimated Manly's selection indices and confidence intervals for the proportions of used habitats compared with the available proportions (Table 1). Selection indices for forests above 800 $\mathrm{m}$ were significantly different from those of lower habitats by being smaller. Standardized selection indices indicated that forests in the range 400-600 m were 1.87 and 5.88 times more selected than habitats at 600-800 and 800-1000 m.

Table 1. Estimated selection indices and Bonferroni confidence intervals for the presence of fairy pittas (Pitta nympha) at different elevations on Jeju Island, Korea.

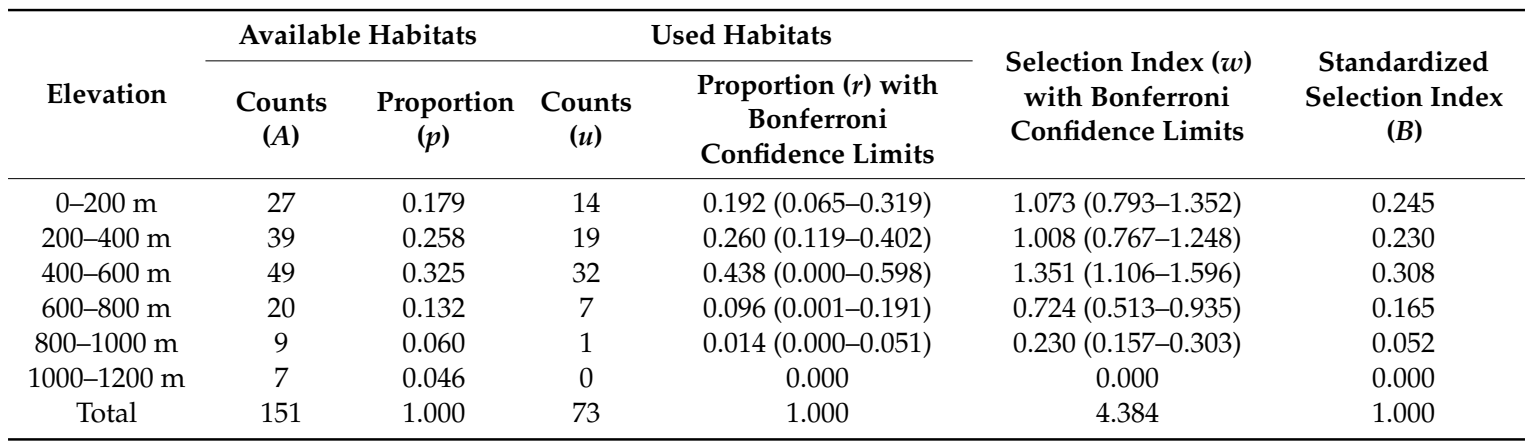

\subsection{Reproductive Performance}

According to the 29 nests found with known breeding parameters, the first egg-laying date was after $174.9 \pm 14.1$ Julian days $(n=26)$ ranging from 157 at $395 \mathrm{~m}$ to 200 at $618 \mathrm{~m}$. There was a general positive relationship between the date and the nesting elevation (coefficient \pm standard error: 0.046 $\pm 0.0163 ; r=0.495, p=0.010$ ) (Figure 2), indicating delayed egg-laying at higher elevations, and in particular, breeding in nests at $<400 \mathrm{~m}$ elevation was 17-20 days earlier than that in nests at higher elevations (Table 2). However, no influence of elevation on clutch size was detected, nor on the number of hatchlings and the number of fledglings, even between the preferred (400-600 m) and avoided elevations (600-800 m) (Table 2). 


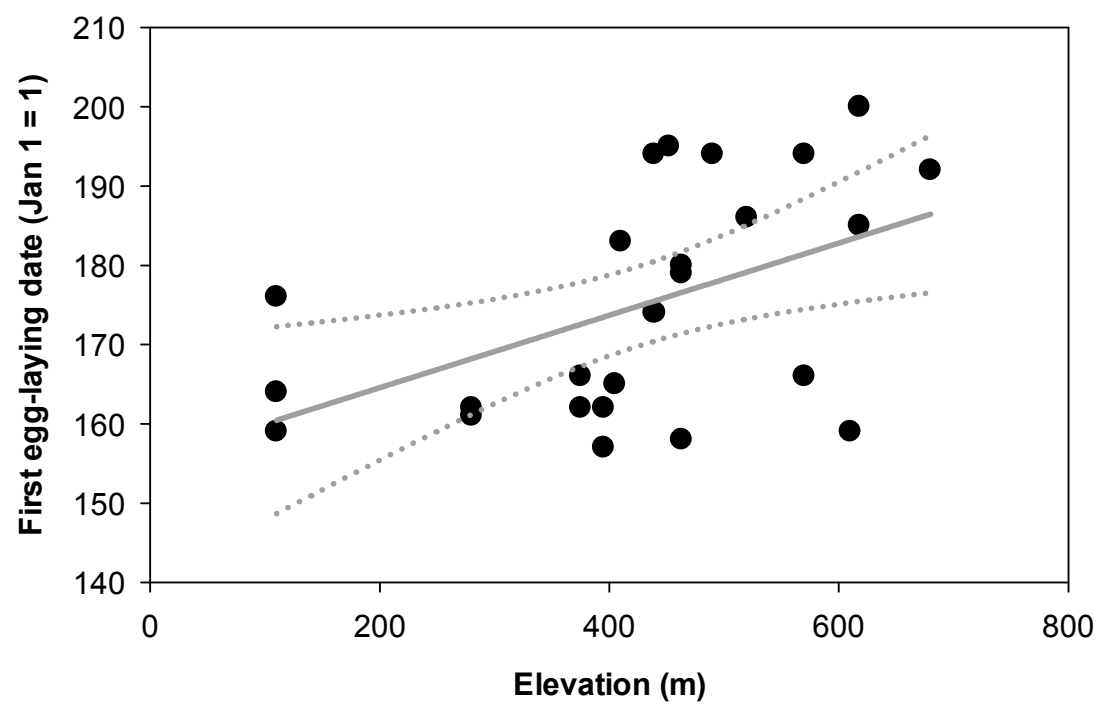

Figure 2. Changes in the first egg-laying dates of fairy pittas by elevation on Jeju Island, Korea. The linear relationship is shown as a solid line (gray) with $95 \%$ confidence intervals (dotted gray).

Table 2. Reproductive parameters (mean \pm SD) of the fairy pitta (Pitta nympha) at three elevations with different preference on Jeju Island, Korea. Different superscript letters indicate significant differences $(p<0.05)$.

\begin{tabular}{|c|c|c|c|c|c|c|c|}
\hline Parameter & $\begin{array}{l}\text { Elevation with } \\
\text { No Preference } \\
(0-400 \mathrm{~m}, n=12)\end{array}$ & $\begin{array}{l}\text { Preferred Elevation } \\
(400-600 \mathrm{~m}, n=13)\end{array}$ & $\begin{array}{c}\text { Avoided } \\
\text { Elevation } \\
(600-800 \mathrm{~m}, n=4)\end{array}$ & $d f$ & $F$ & $H$ & $p$ \\
\hline First egg-laying date & $163.2 \pm 5.4^{\mathrm{a}}$ & $180.2 \pm 12.4^{b}$ & $184.0 \pm 17.8^{b}$ & 2 & 7.303 & & 0.004 \\
\hline Clutch size & $4.7 \pm 0.7$ & $4.5 \pm 0.8$ & $4.8 \pm 1.0$ & 2 & & 0.395 & 0.821 \\
\hline No. hatchlings & $3.4 \pm 2.1$ & $3.6 \pm 1.8$ & $3.8 \pm 2.6$ & 2 & & 0.373 & 0.830 \\
\hline No. fledglings & $3.4 \pm 2.1$ & $3.2 \pm 2.0$ & $3.5 \pm 2.4$ & 2 & & 0.257 & 0.879 \\
\hline
\end{tabular}

\subsection{Changes in Forested Areas}

The overall size of forested areas on Jeju Island remained nearly the same ( $2 \%$ increase in size) between 1975 and 2002 (Table 3). However, the area of preferred forest habitats at 400-600 m increased from 80 to $128 \mathrm{~km}^{2}$, while coastal zones were deforested during the three decades (Table 3, Figure 3). Constructed forest maps also show deforestation and fragmentation of forested areas at lower elevations on the coast, but reforestation at the 400-600 m elevation zone (Figure 3).

Table 3. Changes in forested areas on Jeju Island between 1975 and 2002 in three different elevations with preference for breeding elevations.

\begin{tabular}{cccc}
\hline \multirow{2}{*}{ Elevation by Habitat Preference } & \multicolumn{2}{c}{ Forested Area $\mathbf{( k m}^{\mathbf{2}}$ ) } & \multirow{2}{*}{ Difference (Change in \%) } \\
\cline { 2 - 3 } & $\mathbf{1 9 7 5}$ & $\mathbf{2 0 0 2}$ & \\
\hline$<400$ m (elevation with no preference) & 592.1 & 555.5 & $-36.6(-6.2 \%)$ \\
$400-600$ m (preferred elevation) & 79.8 & 127.8 & $48.0(60.3 \%)$ \\
$>600$ m (avoided elevation) & 226.1 & 232.3 & $6.2(2.7 \%)$ \\
Total & 898.0 & 915.6 & $17.6(2.0 \%)$ \\
\hline
\end{tabular}



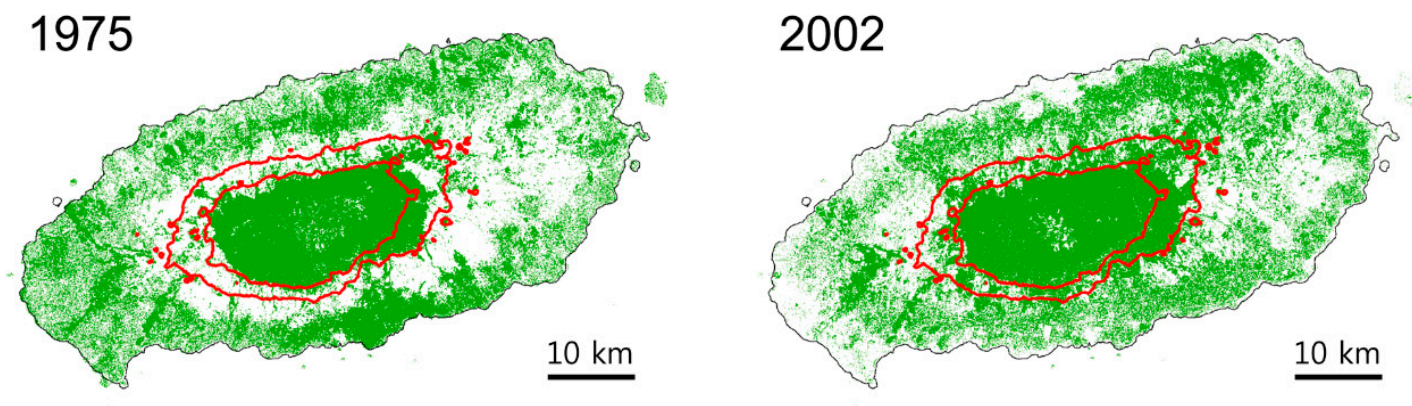

Figure 3. Changes in forested areas (marked green) between 1975 (left) and 2002 (right) on Jeju Island, Korea. The two bold red lines around Mount Halla in the center of the island indicate 400 and $600 \mathrm{~m}$ contours, and the areas between the two contours are at the breeding elevations preferred by the fairy pitta.

\section{Discussion}

The results of this study indicated that there was clear elevation preference and avoidance for breeding by the threatened fairy pitta on Jeju Island, the stronghold of the national population. However, contrary to our expectation, no preference of the pitta for elevations below $400 \mathrm{~m}$ for breeding habitat was detected. Instead, forests at 400-600 m were strongly preferred and selected as the breeding elevation, whereas the higher elevations were clearly avoided. This pattern of elevation preference was supported by three different methods: the predicted chance of presence [23], Jacob's preference index [24], and Manly's selection index [25].

Out of four parameters examined for reproductive performance, only the first egg-laying date showed a significant difference among the three different elevation categories, and the timing of breeding initiation was obviously delayed at elevations above $400 \mathrm{~m}$. This vertical difference in breeding phenology is often caused by weather conditions such as temperature and humidity, as well as by ecological conditions such as prey availability [7,30]. In terms of prey availability, earthworms were the most important food item for nestlings of the pitta and accounted for $>73 \%$ of the food delivered during chick provisioning periods [13]. According to a previous study on prey availability for breeding pittas, the earthworm density in forest floors around the pitta breeding habitat at $100 \mathrm{~m}$ elevation was higher than at $380 \mathrm{~m}$ elevation [31], suggesting a decline in prey availability along the elevation gradient. The distribution, growth, and activity of earthworms are also largely affected by non-biotic factors, such as humidity and temperature [32]. Because Jeju is a very humid island due to the high amount of average precipitation (2309 mm/year) [22,33,34], temperature more strongly affects the vegetation structure of Mount Halla than humidity does [35]. For example, the temperature range most suitable for raising earthworms is known to be $20-25^{\circ} \mathrm{C}$ [36-38], and the forest floor on Mount Halla below $250 \mathrm{~m}$ elevation reaches that temperature range in June and July [35]. However, this temperature range is achieved a month later (July and August) in forests at 500-700 m elevation [35], implying that the occurrence and activity of the main prey for breeding pittas is delayed at higher elevations. The lower temperature and delayed food availability at a higher elevation may result in a delayed start of fairy pitta breeding on Mount Halla. Other studies on forest birds also revealed that the egg-laying date was delayed more in upland areas than in lowland areas for forest birds such as great tits (Parus major L.) [39], varied tits (Poecile varius (Temminck \& Schlegel)) [8], and Tickell's leaf-warblers (Phylloscopus affinis (Tickell)) [40].

On the other hand, the remaining three parameters (clutch size, number of hatchlings, and number of fledglings) were not different among preferred, non-preferred, and avoided elevations. The change in clutch size and its related parameters along the elevation gradient may not have a certain trend when climatic and environmental factors are not actually deterministic for selection, or not predictable in relation to elevation [41]. Similarly, our findings indicated that there was no clear benefit in the pitta's breeding performance due to preference in elevation. As habitat selection patterns may not always 
indicate the optimal choices of a species [2], the result suggests that the pitta's inherent selection for the best reproductive performance was not a key driving factor of the elevation preference observed, and that environmental and external factors may affect the vertical distribution and elevation preference of the breeding pittas.

In many cases, the effects of habitat selection on avian breeding success or fitness are altered or deterred by other biological factors, such as nest predation. In particular, high nest predation rates may place a strong selection pressure on decisions affecting the selection of breeding sites [5,42,43]. Though the selection of a breeding habitat and nest site may often affect breeding success [3], the breeding success of five passerine species in South America, that demonstrated preference in nesting plants, was largely determined by the presence of predators rather than by nesting site preference [4]. Breeding performances of members of the family Laniidae in France were also affected by predation, rather than by nesting selection or preference [44]. As an important process reducing avian breeding success $[45,46]$, nest predation of fairy pittas by corvids on Jeju Island was the most significant natural threat to the breeding pittas [11]. Large-billed crows (Corvus macrorhynchos Wagler) are fairly common nest predators of the pitta and cause $66 \%$ of their nest failures (Kim, unpublished data). The crows are widely distributed throughout the island but are often attracted even to the higher elevations by the high volume of tourists and food waste along trails [47]. The invasive Eurasian magpies (Pica pica (L.)) are also known to be a nest predator of the pitta [11], are increasing in number, and their distribution is expanding at lower elevations, particularly at less than $600 \mathrm{~m}$, on Jeju Island [48]. Therefore, though the breeding performances observed under the existing predation risk remained the same up to $800 \mathrm{~m}$ in this study, the expected breeding performances would be better, especially at lower elevations, if no predation by invasive corvids were to happen.

In addition to the higher predator density at lower elevations, negative human impacts on pitta survival, such as car accidents and window strikes also occur at lower elevations [11]. This kind of mortality not directly related to reproduction was not considered in our reproductive performance measurements. Because the overall proportion of anthropogenic causes of non-reproductive mortality could be higher than that of natural causes in fairy pittas on Jeju Island [11], the breeding pittas might be more exposed to the greater human footprint in deforested areas at lower elevations.

While the overall size of forested areas remained nearly the same and coastal areas were deforested between 1975 and 2002, the area of forests in the range of elevations pittas prefer increased from 80 to $128 \mathrm{~km}^{2}$. In addition, evergreen broadleaved forest, which is the preferred breeding environment for pittas [15], is currently dominant up to $600 \mathrm{~m}$ on Mount Halla [19]. Kim et al. [21] described that this increase of potential breeding habitat and the development of evergreen broadleaved forest are largely the result of reforestation in the mid-mountain areas between 200 and $600 \mathrm{~m}$ after the $1980 \mathrm{~s}$. The reforestation on Jeju Island has probably improved breeding habitats, but the Jeju Dwarf Bamboo (Sasa quelpaertensis Nakai) at higher elevations reduces the potential breeding and feeding habitats for the pittas by covering the forest floors [49]. As reforestation proceeds on Mount Halla, the dwarf bamboo colonies are also expanding into reforested areas at lower elevations [34], resulting in the potential for degradation of breeding habitat for the pittas.

\section{Conclusions}

As previously reported [14,21], fairy pittas clearly avoided higher mountain areas (above $600 \mathrm{~m}$ ) for breeding habitat on Jeju Island. This might have been caused by the lower temperature, a delayed breeding season, lower prey abundance, and less broad-leaved forest areas, along with expanding Jeju dwarf bamboo on forest floors. On the other hand, forested areas lower than $400 \mathrm{~m}$ are expected to be advantageous for the breeding pittas because of higher temperatures and higher prey abundances (represented by earthworms) that clearly allowed the pittas to attempt earlier breeding. Despite the advantages at the lower elevations, significant preference was not detected and better reproductive outcomes were not guaranteed. That may be because of increasing environmental pressures including deforestation, habitat degradation, and human-related, non-reproductive mortality in the coastal zone. 
Consequently, this study identified that the elevation range $400-600 \mathrm{~m}$ provided the currently preferred breeding habitat for the threatened fairy pittas on Jeju Island. This observed pattern in the preferred elevations might be a response to external and environmental factors-possible tradeoffs between upward shifts by human-related impacts (i.e., habitat loss and degradation, non-reproductive mortality, and higher predator density) and downward shifts by vertically graduated environmental parameters (i.e., temperature, vegetation, prey abundance)—rather than an inherent optimal selection for the best reproductive outcomes.

Despite no preference for them during breeding habitat selection by elevation, forested areas at lower elevation still provide critical breeding habitats for the threatened fairy pittas because the low forests have greater potential to host more breeding pairs in their four-times-larger area $\left(555.5 \mathrm{~km}^{2}\right)$ than in the forest area at preferred elevations $\left(127.8 \mathrm{~km}^{2}\right)$. Therefore, it is important to maintain good breeding populations in the lower elevation forests for the conservation of the overall population on Jeju Island. Increasing the preferred breeding habitat in size may benefit declining and threatened avian populations, and higher temperatures and prey abundance are still positive factors for increasing habitat preference and reproductive outcomes of the pitta at lower elevations. However, human impacts and development pressure on the mid-mountain region and coastal areas of Jeju Island are rapidly increasing [50]. Therefore, increasing human-pitta conflicts, habitat loss and degradation by on-going coastal developments, and anthropogenic threats and disturbance at lower elevations, should be effectively mitigated for the successful conservation of the threatened pittas on Jeju Island.

Author Contributions: Conceptualization, E.-M.K., C.-W.K., and C.-Y.C.; data curation, E.-M.K.; formal analysis, E.-M.K., C.-W.K., C.-Y.C., and J.-H.C.; funding acquisition, E.-M.K. and C.-W.K.; investigation, E.-M.K., C.-W.K., C.-Y.C., and H.-Y.N.; methodology, C.-Y.C., J.-H.C., and H.-Y.N.; project administration, E.-M.K. and C.-W.K.; software, J.-H.C.; supervision, C.-Y.C.; visualization, C.-Y.C. and J.-H.C.; writing-original draft, E.-M.K., C.-Y.C., and H.-Y.N.; writing-review and editing, C.-W.K., C.-Y.C., J.-H.C., and H.-Y.N.

Funding: The main parts of the fieldwork were funded by the Korea Association for Bird Protection Jeju Branch with the support of the Warm Temperate and Subtropical Forest Research Center, National Institute of Forest Sciences. Field surveys in 2017 were also supported by the endangered species monitoring program of the National Institute of Biological Resources.

Acknowledgments: We thank Mirae Oh as well as the staff of the Jeju Wildlife Rescue and Rehabilitation Center who helped our fieldwork.

Conflicts of Interest: The authors declare no conflict of interest.

\section{References}

1. Southwood, T.R.E. Habitat, the templet for ecological strategies? J. Anim. Ecol. 1977, 46, 337-366. [CrossRef]

2. Clark, R.G.; Shutler, D. Avian habitat selection: Pattern from process in nest-site use by ducks? Ecology 1999, 80, 272-287. [CrossRef]

3. Avilés, J.M.; Sánchez, J.M.; Parejo, D. Nest-site selection and breeding success in the Roller (Coracias garrulus) in the Southwest of the Iberian Peninsula. J. Ornithol. 2000, 141, 345-350. [CrossRef]

4. Mezquida, E.T. Nest site selection and nesting success of five species of passerines in a South American open Prosopis Woodland. J. Ornithol. 2004, 145, 16-22. [CrossRef]

5. Li, P.; Martin, T.E. Nest-site selection and nesting success of cavity-nesting birds in high elevation forest drainages. Auk 1991, 108, 405-418.

6. Johnson, L.S.; Ostlind, E.; Brubaker, J.L.; Balenger, S.L.; Johnson, B.G.P.; Golden, H. Changes in egg size and clutch size with elevation in a Wyoming population of Mountain Bluebirds. Condor 2006, 108, 591-600. [CrossRef]

7. Lee, J.K.; Chung, O.K.; Lee, W.S. Altitudinal variation in parental provisioning of nestling Varied Tits (Poecile varius). Wilson J. Ornithol. 2011, 123, 283-288. [CrossRef]

8. Boyle, W.A. Can variation in risk of nest predation explain altitudinal migration in tropical birds? Oecologia 2008, 155, 397-403. [CrossRef] [PubMed]

9. BirdLife International. Threatened Birds of Asia: The BirdLife International Red Data Book; BirdLife International: Cambridge, UK, 2001. 
10. BirdLife International. Pitta Nympha (amended version of 2016 assessment). In The IUCN Red List of Threatened Species 2017: E.T22698684A116880779; BirdLife International: Cambridge, UK, 2017. [CrossRef]

11. Kim, E.M.; Choi, C.Y.; Kang, C.W. Causes of injury and mortality of Fairy Pitta Pitta nympha on Jeju Island, Korea. Forktail 2013, 29, 145-148.

12. Lambert, F.; Woodcock, M. Pittas, Broadbills and Asities; Pica Press: Sussex, UK, 1996.

13. Lin, R.S.; Yao, C.T.; Lee, P.F. The diet of Fairy Pitta Pitta nympha nestling in Taiwan as revealed by videotaping. Zool. Stud. 2007, 46, 355-361.

14. Ko, C.Y.; Lee, P.F.; Bai, M.L.; Lin, R.S. A rule-based species predictive model for the vulnerable Fairy Pitta (Pitta nympha) in Taiwan. Taiwania 2009, 54, 28-36.

15. Kim, E.M.; Oh, H.S.; Kim, S.B.; Kim, W.T. The distribution and habitat environment of Fairy Pitta (Pitta nympha Temminck \& Schlegel) on Jeju Island, Korea. Korean J. Ornithol. 2003, 10, 77-86.

16. Kim, H.K. The ecology of Fairy Pitta. Bull. Korea Cult. Res. Inst. 1964, 5, 235-240.

17. Won, P.O. Report of the Academic Surveys on Mt. Hallasan and Hongdo Island; Ministry of Culture and Information: Seoul, Korea, 1968.

18. Park, H.S.; Kim, W.T. Forest bird surveys in Jeju Island. Cheju National University Journal. 1981, 13, 151-165.

19. Park, H.S. A study on the community structure of forest birds in the northern slope on Mt. Halla. Cheju National University Journal. 1984, 19, 171-183.

20. Kim, E.M. The distribution and breeding ecology of Fairy Pitta (Pitta nympha) on Mt. Halla. In Report of Survey and Study of Hallasan Natural Reserve; Ko, Y.J., Ko, J.G., Eds.; Research Institute for Mt. Halla, Jeju Special Self-governing Province: Jeju, Korea, 2006; pp. 533-545.

21. Kim, E.M.; Kwon, J.O.; Kang, C.W.; Chun, J.H. Causes of the difference of inhabited altitudes above sea level of Fairy Pitta (Pitta nympha) on Jeju Island followed by forest landscape through the comparison of Landsat images and the literature review. J. Korean Assoc. Geogr. Inf. Stud. 2013, 16, 79-90. [CrossRef]

22. Korea Meteorological Administration. The Understanding of Climate Change VI: The Climate Change of Jeju Island; Jeju Regional Meteorological Office, National Institute of Meteorological Research: Jeju, Korea, 2010.

23. Kindt, R.; Coe, R. Tree Diversity Analysis. A manual and Software for Common Statistical Methods for Ecological and Biodiversity Studies; World Agroforestry Centre (ICRAF): Nairobi, Kenya, 2005.

24. Jacobs, J. Quantitative measurement of food selection: A modification of the forage ratio and Ivlev's electivity index. Oecologia 1974, 14, 413-417. [CrossRef] [PubMed]

25. Manly, B.F.; McDonald, L.L.; Thomas, D.; McDonald, T.L.; Erickson, W.P. Resource Selection by Animals: Statistical Design and Analysis for Field Studies; Kluwer Academic Publishers: Boston, MA, USA, 2002.

26. R Development Core Team. R: A Language and Environment for Statistical Computing; R Foundation for Statistical Computing: Vienna, Austria, 2014; Available online: http://www.r-project.org (accessed on 1 June 2015).

27. Markham, B.L.; Barker, J.L. Landsat MSS and TM post-calibration dynamic ranges, exoatmospheric reflectances and at-satellite temperatures. EOSAT Landsat Tech. Notes 1986, 1, 3-8.

28. Teillet, P.M.; Guindon, B.; Goodenough, D.G. On the slope-aspect correction of multispectral scanner data. Can. J. Remote Sens. 1982, 8, 84-106. [CrossRef]

29. Meyer, P.; Itten, K.I.; Kellenberger, T.; Sandmeier, S.; Sandmeier, R. Radiometric corrections of topographically induced effects on Landsat TM data in an alpine environment. ISPRS J. Photogram. Remote Sens. 1993, 48, 17-28. [CrossRef]

30. Badyaev, A.V.; Ghalambor, C.K. Evolution of life histories along elevational gradients: Trade-off between parental care and fecundity. Ecology 2001, 82, 2948-2960. [CrossRef]

31. Kim, E.M.; Choi, H.S.; Kang, C.W.; Min, D.W.; Yang, E.J.; Oh, M.R. Comparative studies on earthworm density by breeding place characteristics of Fairy Pitta on Jeju Island. J. Korean Environ. Res. Tech. 2014, 17, 43-49. [CrossRef]

32. Martin, S.; Lavelle, P. A simulation model of the vertical movements of an earthworm population (Millsonia anomala, Omodeo, Megascolecidae) in an African savanna (Lamto, Ivory Coast). Soil Biol. Biochem. 1992, 24, 1419-1424. [CrossRef]

33. Kim, K.D.; Lee, S.H. The characteristics of folk house related to climate in Cheju Island. J. Korean Assoc. Region. Geogr. 2001, 7, 29-43.

34. Koh, J.G. Global warming and vegetation of Mt. Halla. Research Report on Mt. Halla. 2007, 6, 3-17. 
35. Song, C.K.; Park, Y.M.; Cho, N.K.; Ko, Y.W.; Kang, D.I. Growth responses of some medicinal plants in different altitudes of Mountain Halla. Korean J. Med. Crop Sci. 2000, 8, 134-145.

36. Edwards, C.A. Breakdown of animal, vegetable, and industrial organic wastes by earthworms. In Earthworms in Waste and Environmental Management; Edwards, C.A., Neuhauser, E.F., Eds.; SPB Academic Publishing BV: The Hague, Netherlands, 1988; pp. 21-31.

37. Pawlett, M.; Hopkins, D.W.; Moffett, B.F.; Harris, J.A. The effect of earthworms and liming on soil microbial communities. Biol. Fertil. Soils 2009, 45, 361-369. [CrossRef]

38. Correia, F.V.; Moreira, J.C. Effects of glyphosate and 2, 4-D on earthworms (Eisenia foetida) in laboratory tests. Bull. Environ. Contam. Toxicol. 2010, 85, 264-268. [CrossRef] [PubMed]

39. Beldal, E.J.; Barba, E.; Gil-delgado, J.A.; Iglesias, D.J.; Lopez, G.M.; Monros, J.S. Laying date and clutch size of Great Tits (Parus major) in the Mediterranean region: A comparison of four habitat types. J. für Ornithol. 1998, 139, 269-276. [CrossRef]

40. Lu, X. Breeding ecology of an old world high-altitude warbler, Phylloscopus affinis. J. Ornithol. 2008, 149, 41-47. [CrossRef]

41. Krementz, D.G.; Handford, P. Does avian clutch size increase with altitude? Oikos 1984, 43, $256-259$. [CrossRef]

42. Storch, I. Habitat fragmentation, nest selection, and nest predation risk in Capercaillie. Ornis Scand. 1991, 22, 213-217. [CrossRef]

43. Ortego, J. Consequences of Eagle Owl nest-site habitat preference for breeding performance and territory stability. Ornis Fenn. 2007, 84, 78-90.

44. Isenmann, P.; Fradet, G. Nest site, laying period, and breeding success of the Woodchat shrike (Lanius senator) in Mediterranean France. J. für Ornithol. 1988, 139, 49-54. [CrossRef]

45. Ricklefs, R.E. An analysis of nesting mortality in birds. Smithson. Contrib. Zool. 1969, 9, 1-48. [CrossRef]

46. Mayfield, H. Brown-headed cowbird: Agent of extermination. Am. Birds 1977, 31, 107-113.

47. Park, C.R.; Kim, E.M.; Kang, C.W. Seasonal change of altitudinal occurrence of birds at Mt. Hallasan: Escalator effects? Int. For. Rev. 2010, 12, $24-25$.

48. Park, J.Y.; Kim, B.S.; Oh, H.S. A Study on the breeding density and diet of magpie Pica pica in Jeju Island. Korean J. Environ. Ecol. 2008, 22, 648-657.

49. Kim, C.S. Outline of plants of Hallasan Natural Reserve. In Report of Survey and Study of Hallasan Natural Reserve; Ko, Y.J., Ko, J.G., Eds.; Research Institute for Mt. Halla, Jeju Special Self-governing Province: Jeju, Korea, 2006; pp. 109-137.

50. Nam, H.Y.; Kim, E.M.; Choi, C.Y.; Kang, C.W. Avifauna of Gungdae Oreum and its seasonal changes in the Jeju Eastern Oreum Group in Jeju Island, Korea. J. Asia-Pac. Biodiver 2019, in press. [CrossRef] 